\title{
A retomada dos esforços de $P \& D$ nas telecomunicações brasileiras: uma perspectiva das teorias regulatórias
} Restoring efforts of the Brazilian Telecommunications RED: A Regulatory Theory Approach

Submetido(submitted): 10 de abril de 2013 Parecer(revised): 30 de abril de 2013 Aceito(accepted): $1^{\circ}$ de maio de 2013
Simone Henriqueta Cossetin Scholze*

\section{RESUMO}

Propósito - O objetivo deste ensaio é examinar a adoção de iniciativas de apoio pela agência reguladora brasileira a atividades de $\mathrm{P} \& \mathrm{D}$ em telecomunicações no Brasil, à luz de teorias regulatórias, em especial a regulação por incentivos.

Metodologia/abordagem/design - Trata-se de uma abordagem relativa a dimensões de fato e de direito que envolvem a reforma das telecomunicações no Brasil a partir do fim da década de 1990 e as atividades atuais da Anatel. São examinadas algumas teorias regulatórias, como a teoria do interesse público, que se projetam sobre os rumos da atuação estatal na economia.

Resultados - A aplicação da teoria geral da regulação proposta por Robert Horwitz pode ser útil para aprofundar a consideração da comensurabilidade dos modelos norte-americano e brasileiro de regulação estatal.

Implicações práticas - Busca-se, a partir dessa análise crítica, oferecer uma visão geral e uma abordagem introdutória que ofereça ponto de partida para o aprofundamento posterior das interações dinâmicas entre regulação estatal e políticas públicas de P\&D.

Originalidade/relevância do texto - $\mathrm{O}$ texto busca aportar uma contribuição no sentido de identificar elementos da ordem jurídico-institucional e da esfera teórica que permitam lançar um novo olhar sobre as razões e a legitimidade do exercício inédito dessa função pelo órgão regulador brasileiro no campo da P\&D.

*Doutoranda em Direito, Estado e Constituição e mestre em Direito e Estado pela Universidade de Brasília. Bacharela em Direito pela Universidade Federal do Rio Grande do Sul. A autora é analista de ciência e tecnologia do Ministério da Ciência e Tecnologia desde 1988, tendo atuado por dez anos como assessora especial do gabinete do ministro. De 2003 a 2007, foi chefe da Seção de Ética da Ciência e Tecnologia da Unesco, em Paris, e coordenou a Comissão Mundial da Ética do Conhecimento Científico e Tecnológico (Comest). De 2007 a 2011, foi Superintendente Executiva da Agência Nacional de Telecomunicações (ANATEL). Atualmente realiza doutorado em Direito na UnB. Contato: simone.scholze@uol.com.br. 
Palavras-chave: regulação; telecomunicações; ANATEL; P\&D; ciência e tecnologia; privatizações.

\section{ABSTRACT}

Purpose - The purpose of this study is to examine initiatives adopted by the Brazilian regulatory agency in support of $R \& D$ activities in the Brazilian telecommunications, in the light of some regulatory theories, particularly incentive regulation.

Methodology/approach/design - The telecommunications reform in Brazil from the end of the 1990s up to Anatel's current activities are seen through a fact and law approach. Analysis is made of regulatory theories that have been projected over the course of state action in the economic field, such as the theory of the public interest. Findings - The application of the study of Robert Horwitz may be useful for further commensurability consideration of U.S. and Brazilian state regulation models.

Practical implications - This critical analysis seeks to provide an overview and an introductory approach that offers a starting point for further knowledge deepening of the interactions between state regulation and $R \& D$ public policies.

Originality/value - The text proposes a contribution towards identifying elements in the legal-institutional and theoretical sphere that allow for a renewed view over the reasons and the legitimacy of such unprecedented role taken by the Brazilian regulatory body in the field of $R \& D$.

Keywords: regulation; telecommunications; Anatel; $R \& D$; science and technology; privatization.

\section{Introdução}

Prevalece hoje mundialmente o entendimento de que as vantagens comparativas dos países residem, em grande medida, na capacidade de criar e utilizar novas tecnologias, a rapidez de sua absorção pelo setor produtivo e a eficiência da aplicação dessas inovações tecnológicas pela sociedade. Isso é especialmente notável com a revolução das Tecnologias da Informação e Comunicações (TICs), que abrangem as telecomunicações e que introduzem profundas mudanças no modo de vida individual, na sociedade e no cenário econômico global em sintonia com o Livro Verde da 
Sociedade da Informação (Brasil 2000, p. 6). Esses avanços científicos e tecnológicos provocam impactos nas mais diversas esferas da vida contemporânea, desde a rotina do individuo à geopolítica das nações.

No entanto, o Brasil mostra-se hoje fortemente dependente de tecnologias externas, sobretudo no segmento de equipamentos de telecomunicações, e o mercado nacional é amplamente dominado por firmas multinacionais, que operam com escalas muito superiores quando comparadas às firmas nacionais.

Assim, apesar dos investimentos expressivos realizados na expansão da planta de telecomunicações no Brasil ao longo dos últimos anos, a maior parte desses recursos é empregada na importação de soluções e tecnologias, com baixa escala de contribuição para o desenvolvimento de conteúdo tecnológico local e gerando, entre outros impactos, forte desequilíbrio na balança comercial.

À luz desse cenário, em anos recentes a Agência Nacional de Telecomunicações (ANATEL) passou a adotar, de modo inédito, uma série de medidas regulatórias afetas ao apoio a atividades de pesquisa e desenvolvimento (P\&D) em telecomunicações no Brasil. De fato, desde a reforma das telecomunicações no Brasil a partir de meados da década de 1990, com o processo de privatização, pouca ou nenhuma política pública foi dirigida a esse setor específico. A retomada dos esforços estatais nesse campo está a merecer uma reflexão aprofundada, sobretudo à luz do dinamismo dos avanços tecnológicos e seus amplos impactos na sociedade

O presente estudo examinará as dimensões de fato e de direito que envolvem a reforma das telecomunicações no Brasil a partir do fim da década de 1990, além das atividades que a ANATEL vem conduzindo no campo do estímulo a atividades de pesquisa, desenvolvimento e inovação. Busca-se identificar elementos da ordem jurídico-institucional e da esfera teórica que permitam lançar um novo olhar sobre as razões e a legitimidade do exercício inédito dessa função pelo órgão regulador brasileiro no campo da P\&D.

São inicialmente identificados o amparo constitucional e a base legal da reforma das telecomunicações, notadamente a Lei Geral de Telecomunicações (LGT) e sua regulamentação subsequente, que conformam a atuação da agência reguladora. Examinam-se, em seguida, as 
diversas iniciativas da ANATEL que configuram a tendência de retomada dos esforços estatais de $\mathrm{P} \& \mathrm{D}$ em telecomunicações pela via da atuação regulatória.

A busca dos parâmetros conceituais de reflexão encontram nas teorias regulatórias norte-americanas elementos para aprofundar a crítica ao direito, quando a administração do Estado se investe em tarefas de planejamento, prestação de serviços e implantação de infraestrutura, impulsionadas pelo dinamismo científico e tecnológico, que caracteriza o campo das telecomunicações. São, para tanto, elencadas e examinadas criticamente teorias da regulação que se projetam sobre a atuação estatal nesse setor. $\mathrm{O}$ texto obviamente não pretende eleger uma teoria que descreva exaustivamente e oriente com segurança o fenômeno regulatório nesse campo, mas detém-se na possibilidade de aplicação ao caso brasileiro do estudo de Robert Horwitz (1989), em seu livro The Irony of Regulatory Reform: The Deregulation of American Telecommunication, que se mostra um útil e vigoroso instrumento de análise e proposição de uma nova teoria geral da regulação. Essa base teórica apresenta-se viável para permitir a consideração da comensurabilidade dos modelos norte-americano e brasileiro de regulação estatal e de políticas públicas em P\&D no campo das telecomunicações.

$\mathrm{O}$ texto não pretende eleger uma teoria que descreva exaustivamente $\mathrm{e}$ oriente com absoluta segurança o processo regulatório nessa área, mas busca aportar uma contribuição no sentido de identificar elementos da ordem jurídico-institucional e da esfera teórica que permitam lançar um novo olhar sobre as razões e a legitimidade do exercício inédito dessa função pelo órgão regulador brasileiro no campo da $\mathrm{P} \& \mathrm{D}$.

\section{A base legal da reforma das telecomunicações e a regulação estatal}

Na segunda metade da década de 1990, o Brasil vivenciou o processo de reforma do Estado, com a redução de sua participação como agente econômico, e a reorganização de dimensões importantes dos serviços públicos. Realizaram-se privatizações de setores sob monopólio público, como energia, petróleo, transportes e telecomunicações, além de reformas no sistema de ciência e tecnologia, envolvendo, entre outras iniciativas, o 
estabelecimento de novos mecanismos legais, e mais estáveis do que o orçamento setorial, de financiamento à pesquisa científica e ao desenvolvimento tecnológico (P\&D), sobretudo nas áreas recémprivatizadas, mediante a criação dos Fundos Setoriais de financiamento à pesquisa e à inovação.

Em consonância com as tendências mundiais nas telecomunicações, a reformulação do Sistema Telebrás no Brasil pode ser resumido em duas proposições basilares: as empresas estatais de prestação de serviços seriam transferidas para a iniciativa privada; e não mais deveria haver monopólio em sua prestação, sendo necessário instaurar a competição entre empresas. Para assegurar a realização dessas proposições, o fim do monopólio estatal nas telecomunicações foi inscrito na Emenda Constitucional no 8, de 1995. ${ }^{1}$

$\mathrm{O}$ processo de desestatização das telecomunicações no Brasil comportou, em especial, os desafios da construção de uma nova institucionalidade regulatória e de uma base jurídica inovadora, fundada na prevalência do interesse público, ${ }^{2}$ nas considerações do mercado e na atenção às orientações da política setorial. Centrou-se na implantação de um modelo concorrencial para a prestação dos serviços e na efetivação de direitos econômicos fundamentais, particularizados na Lei 9.472/1997, a

${ }^{1}$ As agências reguladoras, como categoria abstrata, não receberam disciplina constitucional. O texto da Constituição, todavia, faz menção a duas: a de telecomunicações (art. 21, XI) e a do petróleo (art. 177, § $2^{\circ}$, III), além de contemplar a função estatal de regulação da economia de forma dispersa, ao longo do Capítulo da Ordem Econômica, e de forma explícita, no art. 174, ao estabelecer que o Estado exerce o papel de agente normativo da atividade econômica.

${ }^{2}$ Conferir a Exposição de Motivos no 231, de 10/12/1996, que submete o Projeto de Lei, que versa sobre a nova organização dos serviços de telecomunicações, sobre a criação de um órgão regulador, e sobre outros aspectos institucionais desse setor, em atendimento à Emenda Constitucional $\mathrm{n}^{0}$ 8, de 15 de agosto de 1995. Entre as numerosas referências ao "interesse público" como fator motivador e fundamento da iniciativa, note-se em especial o seguinte trecho: "Há também a considerar que a desestatização prevista por este Projeto estará sendo realizada simultaneamente com a introdução, em setor até então monopolista, de um regime que, embora de competição, manterá a obrigação dos prestadores com o atendimento de caráter social, ou seja, com o denominado serviço universal. O compromisso entre competição e serviço universal é matéria que exigirá que todo o processo (...) esteja subordinado a um complexo esquema de conciliação entre as pressões de mercado e 0 atendimento do interesse público." 
Lei Geral de Telecomunicações (LGT), como direitos dos usuários desses serviços.

Resultado imediato dessas mudanças legais inerentes à dimensão de um Estado Regulador, ${ }^{3}$ as agências reguladoras surgem como um novo instrumento de atuação do Estado no domínio econômico. A LGT atribuiu à União, por intermédio de um órgão regulador autônomo, a Agência Nacional de Telecomunicações (ANATEL), a incumbência de organizar a exploração dos serviços, incluídas sua execução, comercialização e uso, a implantação e funcionamento de redes de telecomunicações, bem como a utilização do espectro de radiofrequências e dos recursos orbitais (art. $1^{\circ}$ ). Prescreveu que o objetivo da regulação é garantir o direito de toda a população de acesso às telecomunicações, a preços razoáveis e condições adequadas $\left(\operatorname{art} .2^{\circ}\right)$.

$\mathrm{O}$ art. $4 .^{\circ}$ da LGT elenca os princípios constitucionais que condicionam a validade da regulação, quais sejam: da soberania nacional, função social da propriedade, liberdade de iniciativa, livre concorrência, defesa do consumidor, redução das desigualdades regionais e sociais, repressão ao abuso do poder econômico e continuidade do serviço prestado no regime público. Para a adequada implementação de suas competências e a salvaguarda desses direitos, ao novo órgão regulador, considerado autarquia especial em face de poderes ampliados que detém, foi delegada a responsabilidade de realização de processo normativo para a formulação de regulamentos.

A flexibilidade da estrutura jurídica buscou permitir a absorção das transformações do setor, sem constante revisão do modelo. Como ressalta Carlos Ari Sundfeld (2000, p. 17-38), o caráter aberto da regulação decorre de sua capacidade de incorporar mudanças trazidas pelas inovações

3“(...) o Estado Social assume hoje a forma moderna de Estado Regulador de serviços públicos essenciais" (CANOTILHO 2003, p. 352). As agências representam a substituição do modelo de gestão com base em controles formais e intervenção direta (estado empresário), pelo modelo gerencial, com base em avaliação de desempenho (eficiência) e intervenção condicionante da eficiência (regulação e regulamentação). Ou seja, nem o estado mínimo, protetor das liberdades (estado de direito liberal), nem o estado promotor de benefícios sociais e econômicos (estado social), mas o estado que contribui para o aprimoramento das eficiências do mercado (estado regulador).

Revista de Direito, Estado e Telecomunicações, v. 5, n. 1, p. 107-134 (2013)

DOI: https://doi.org/10.26512/lstr.v5i1.21564 
tecnológicas e evolução do mercado, sem necessidade de edição de novas leis.

A LGT conferiu, portanto, caráter de especificidade às telecomunicações, desvinculando-se dos modelos do direito administrativo econômico, passando a submetê-las a disciplina própria. ${ }^{4}$ Inovou ao mudar conceitos até então vigentes, como os de serviço público, serviço privado, concessão e autorização, inaplicabilidade das leis gerais de licitação e nova estrutura de mercado, com competição e regulação assimétrica. Instaurou dois regimes de prestação dos serviços - um público, que adota as regras de universalização e continuidade; e outro, privado, subordinado aos princípios da exploração de atividades econômicas. ${ }^{5}$

Ademais, conforme explicitado na Exposição de Motivos 231/1996, a LGT criou "um novo ente a exercitar competências de poder público, sem compromisso maior com o perfil tradicional dos entes governamentais" (Brasil 1996, p. 34). Esse novo ente é a agência reguladora independente, de natureza fiducial e dotada da competência de emitir normas sobre os serviços de telecomunicações nos regimes público e privado (incisos IV e $\mathrm{X}$ do art. 19 da LGT). ${ }^{6}$ À Anatel caberia adotar as medidas necessárias para o

${ }^{4} \mathrm{~A}$ reforma das telecomunicações no Brasil pode ser ilustrativa de algumas das consequências, apontadas por Castro relativamente às articulações do direito contemporâneo quanto à penetração das "formas" das políticas públicas no conjunto das "formas" herdadas do passado (CASTRO 2012, p. 203-204). Trata-se também de processo típico da common law assimilado pelo direito brasileiro no caso da legislação de telecomunicações, a ponto de alguns autores, como Sundfeld identificarem a emergência de um direito de telecomunicações (SUNDFELD 2006/2007, p. 4).

5“As inovações introduzidas na Lei Geral de Telecomunicações brasileira de 1997 pertinentes aos conceitos de serviços de interesse coletivo e de interesse restrito temperam a diferença que existia entre os serviços de interesse público dos EUA e os serviços públicos brasileiros no setor de telecomunicações e permitem dizer que, hoje, as políticas públicas de ambos os países são comensuráveis quanto ao tratamento dos serviços e são comensuráveis a tal ponto de permitir a identificação de passos sobre tema específico como o é o do serviço universal" (ARANHA, 2005, p. 193).

${ }^{6}$ A propósito do debate doutrinário e judicial sobre a extensão da independência administrativa e do poder normativo da ANATEL, ver manifestações dos ministros do STF no âmbito da ADIN 1.668-5/DF e ADIN 1.949-0/RS. Quanto à delegação instrumental de competência do Estado como agente regulador da atividade 
atendimento do interesse público e para o desenvolvimento das telecomunicações brasileiras (caput, art. 19).

Assim como a LGT, as leis instituidoras de outras agências reguladoras implantadas naquele período também se revelam importantes instrumentos da realização de políticas finalísticas. ${ }^{7}$ Dessa forma, a Lei ${ }^{0}$ 9.427/96 atribui à Agência Nacional de Energia Elétrica (ANEEL) a competência para "implementar as políticas e diretrizes do governo federal para a exploração de energia elétrica e o aproveitamento dos potenciais hidráulicos" ( $\operatorname{art.} 3^{\circ}$, I) e a Lei no $9.478 / 97$ estabelece que à Agência Nacional do Petróleo (ANP) compete "implementar (...) a política nacional de petróleo e gás natural (...) com ênfase na garantia do suprimento de derivados de petróleo em todo o território nacional e na proteção dos interesses dos consumidores quanto a preço, qualidade e oferta dos produtos" (art. $\left.8^{\circ}, \mathrm{I}\right)$.

Dispõe ainda a LGT sobre a criação de um fundo - o FUNTTEL - para o desenvolvimento tecnológico das telecomunicações brasileiras. ${ }^{8}$

Com efeito, constata-se que a instrumentalização das normas jurídicas trouxe a técnica como meio de aferição desses instrumentos em sua relação de adequação e realização dos fins (ARAGÃO 2003, p. 24). Distintamente da norma jurídica, a norma técnica não se impõe pela coerção, pois por não ter aplicabilidade imediata, requer o acordo dos interessados quanto ao seu conteúdo. O direito apresenta-se como um instrumento a serviço de políticas mais amplas.

No entanto, em benefício dos investimentos necessários à instalação e ampliação das redes de telecomunicações a todo o território nacional - a

econômica, vide FERRAZ Jr. (2011), texto consultado em 21.10.2012, em http://www.terciosampaioferrazjr.com.br/?q=/publicacoes-cientificas/79.

${ }^{7}$ Debruçando-se sobre a distinção entre as leis que definem as políticas de Estado e os marcos regulatórios, Marques Neto (2005, p. 92) adverte para os limites entre políticas públicas e políticas regulatórias.

${ }^{8} \mathrm{O}$ FUNTTEL completou uma década de existência com um balanço de investimentos de quase R \$ 1 bilhão para projetos de inovação tecnológica na área. De novembro de 2000, quando foi criado, até 2010, o FUNTTEL destinou R \$ 942,7 milhões, tanto em empresas quanto em institutos públicos de pesquisa. O Fundo passou por fortes contingenciamentos ao longo de sua existência. Os outros fundos da área de telecomunicações são o FUST e o FISTEL.

Revista de Direito, Estado e Telecomunicações, v. 5, n. 1, p. 107-134 (2013)

DOI: https://doi.org/10.26512/1str.v5i1.21564 
universalização - e à melhora na qualidade dos serviços, verificou-se então a renúncia, por parte das políticas públicas, aos investimentos diretos em pesquisa e inovação em equipamentos e sistemas de telecomunicações. ${ }^{9}$

\section{Retomada dos esforços estatais de P\&D em telecomunicações via atuação regulatória}

A efetividade do papel que as telecomunicações desempenham no desenvolvimento socioeconômico passaram a depender diretamente da existência e capacidade das infraestruturas de redes e do aporte tecnológico a elas associado. Pressupõe-se que redes modernas, seguras, confiáveis e de alta capacidade resultam no incremento da produtividade em outros setores da economia, além de prover melhores condições de vida a todos (CASTELLS 1999, p. 565).$^{10}$ Conditio sine qua non para a qualidade dos serviços, o fator essencial para manter uma rede de telecomunicações atualizada e adequada às necessidades dos usuários é sua permanente atualização tecnológica.

Para manter uma rede de telecomunicações atualizada e adequada às necessidades dos usuários, é necessária sua constante atualização tecnológica. Essa condição tornou os países em desenvolvimento tecnologicamente dependentes dos países desenvolvidos, caracterizando-os como "exportadores de solução". Nesse sentido, apesar dos investimentos realizados pelo setor de telecomunicações no Brasil ao longo dos últimos anos, ${ }^{11}$ a maior parte desses recursos é empregada na importação de soluções e tecnologias, com baixa escala de contribuição para o

${ }^{9}$ Conferir ERBER (2000) e Estudos Setoriais de Inovação: Indústria de Tecnologia da Informação e Comunicação, ABDI, 2009, em http://www.abdi.com.br/.

${ }^{10} E$ É interessante notar que a noção de rede, em suas variadas acepções, permeia a Sociedade da Informação, desde as infraestruturas de redes físicas ao conceito de novas formas de organização social em redes introduzido por Manuel Castells. A sociedade em rede na era da informação gera uma crise do Estado, pois a estrutura de redes transcende a força dos grupos de poder nacionais.

${ }^{11}$ Ao se considerarem os principais serviços de telecomunicações (STFC, SMP, SCM e TV por assinatura), os investimentos no período de 1999 a 2006 são superiores a $\mathrm{R} \$ 118$ bilhões. Conferir: BRASIL. ANATEL. Estudo Técnico para Atualização da Regulamentação das Telecomunicações no Brasil. 2008, p. 74. 
desenvolvimento de conteúdo tecnológico local e gerando forte desequilíbrio na balança comercial (DE NEGRI e RIBEIRO, 2010, p. 9).

Por um lado, as telecomunicações têm-se mostrado fundamentais para o avanço do país sob um enfoque amplo. Os números do setor mostram sua representatividade na economia nacional, alcançando cerca de $6 \%$ do PIB nacional (BRASIL 2008, p. 229). ${ }^{12}$ As projeções são alavancadas pela expectativa de demanda associada ao advento dos grandes eventos esportivos que o país recepcionará nos anos próximos. Outro fato que se espera resulte em novos investimentos refere-se às licitações das frequência de $450 \mathrm{MHz}, 2,5 \mathrm{GHz}$ e 3,5 GHz, no contexto do Plano Nacional de Banda Larga, ${ }^{13}$ que se espera contribua para a massificação da internet e a introdução da quarta geração da telefonia móvel.

Por outro lado, são preocupantes o alto grau de dependência de tecnologias externas, sobretudo no segmento de equipamentos, e o domínio do mercado nacional por parte de firmas estrangeiras, que operam com escalas muito superiores quando comparadas sob todos os critérios às firmas nacionais (KUBOTA e MILANI 2010). Com efeito, para um mercado sensível a preço, como o caso brasileiro, é importante tornar disponíveis equipamentos de telecomunicações a preços módicos, de modo a permitir a prestação de serviços em larga escala e baixas receitas por usuário.

A aparente consideração desses entraves por parte do governo federal tem levado à retomada, em anos recentes, do debate acerca do desenvolvimento da indústria nacional em telecomunicações, de forma a, entre outros objetivos, reduzir os custos de produção e a dependência de tecnologia externa, nos termos do PNBL instituído pelo Decreto $\mathrm{n}^{\circ}$ $7.175 / 2010$. Ponto crítico para a condução dessa tarefa refere-se a como aproveitar o ecossistema das telecomunicações brasileiras para promover a inovação tecnológica no Brasil, explorando a sinergia entre provedores de serviços, fabricantes e institutos de pesquisa, criando um ciclo onde investimento em $\mathrm{P} \& \mathrm{D}$ resulte em benefícios para o próprio setor ao

${ }^{12} \mathrm{O}$ mercado brasileiro de telecomunicações está em quinto lugar no ranking mundial. Estimativas da ANATEL indicam que a projeção dos investimentos no setor, levando em conta os principais serviços no período de 2008 a 2018, pode alcançar o valor acumulado de $\mathrm{R} \$ 250$ bilhões.

${ }^{13}$ Decreto $n^{0} 7.175 / 2010$, que institui o Programa Nacional de Banda Larga (PNBL).

Revista de Direito, Estado e Telecomunicações, v. 5, n. 1, p. 107-134 (2013)

DOI: https://doi.org/10.26512/1str.v5i1.21564 
reduzirem-se custos e dependência externa. Em um setor de escala expressiva e tecnologicamente sensível, é oportuno investigar a margem de retorno para a economia nacional caso percentual dos investimentos fossem canalizados para o desenvolvimento interno de indústrias e operadoras aqui atuantes.

Nessa conjuntura, a agência reguladora pode desempenhar papel importante por dispor de mecanismos para a promoção de inovação no setor regulado, mediante alavancas regulatórias que permitem estimular as empresas a investirem em pesquisa, desenvolvimento e inovação (PD\&I) em troca de benefícios e vantagens. Trata-se de uma abordagem que vai além da regulação impositiva, onde o órgão regulador determina obrigações em instrumentos específicos como editais de radiofrequência, atos de concentração, cautelares e processos sancionatórios. Trata-se, primordialmente, da regulação por incentivos.

Ao final de 2008, a aprovaçao do Plano Geral de Atualização da Regulamentação da ANATEL (PGR), por meio da publicação da Resolução $\mathrm{n}^{\mathrm{o}}$ 516/08, representou importante ponto de inflexão no planejamento da atuação regulatória da agência. O PGR deu concretude à previsão legal de atuação da Agência no campo do estímulo à $\mathrm{P} \& \mathrm{D}$ mediante a previsão de edição de um "Regulamento de Estímulo a Pesquisa, Desenvolvimento, Inovação em Telecomunicações", ora em consulta pública. ${ }^{14}$

Além de inaugurar esse tema no exercício de sua competência normativo-regulatória, a ANATEL também estabeleceu em 2008 uma série de condicionamentos no processo de anuência prévia à operação de aquisição da Brasil Telecom pela Oi Telemar, entre os quais se destaca a obrigação de investimento em pesquisa e desenvolvimento tecnológico, inclusive por meio de parcerias com centros de excelência e a cessão de capacidade de transmissão em fibras óticas para uso não comercial pela Rede Nacional de Ensino e Pesquisa (RNP). ${ }^{15}$ Dado o êxito alcançado, esse

${ }^{14}$ Consulta Pública ${ }^{0}$ 6, de 13/02/13, que trata da proposta de "Regulamento de Estímulo a Pesquisa, Desenvolvimento, Inovação em Telecomunicações", conforme texto consultado em 14/03/13, no sítio eletrônico http://sistemas.anatel.gov.br/.

${ }^{15}$ Ato $\mathrm{n}^{\mathrm{O}} 7.828 / 2008$, do Conselho Diretor da ANATEL, Item 9. Em decorrência desses condicionamentos, a RNP/MCTI incrementou em 280\% a capacidade agregada de interconexão no período de 2008 a 2011, passando a disponibilizar 
condicionamento foi replicado posteriormente pela agência para a região de São Paulo, por ocasião da anuência prévia à operação societária entre a Telefônica e a Vivo. ${ }^{16}$

O fundamento legal invocado pela Agência para tais iniciativas remete ao art. $2^{\circ}$ da LGT, que determina que o poder público tem o dever de estimular a expansão do uso de redes e serviços de telecomunicações, criar oportunidades de investimento e estimular o desenvolvimento tecnológico e industrial em ambiente competitivo, além de criar condições para que o desenvolvimento do setor seja harmônico com as metas de desenvolvimento social. ${ }^{17}$

A par dos avanços expressivos, após 15 anos de vigência do novo modelo das telecomunicações, associados à retomada do crescimento da economia e do dinamismo tecnológico, a avaliação do cenário atual permite constatar que esse processo foi também acompanhado de importante desnacionalização das empresas do setor, tanto das prestadoras de serviços quanto da indústria de equipamentos e sistemas. ${ }^{18} \mathrm{~A}$ despeito de o art. $2^{\circ} \mathrm{da}$ LGT determinar que o Poder Público tem o dever de criar oportunidades de investimento e desenvolvimento tecnológico e industrial em ambiente competitivo, pouco fora feito até então para dar concretude ao ditame legal.

O cenário brasileiro tem-se mostrado promissor em face da estabilidade econômica e do crescimento de seu mercado interno, mas é fortemente

conexões multigigabits (acima de 1Gbps) para instituições federais em 24 unidades da federação. http://www.rnp.br/noticias/2011/not-1100715.html.

${ }^{16}$ Ato ${ }^{\circ} 6.235 / 2010$, do Conselho Diretor da ANATEL, de 27/09/10.

${ }^{17}$ A esse propósito, conferir: LGT, arts. $2^{\circ}, 19,22,76,77$ e 78.

${ }^{18} \mathrm{~A}$ desnacionalização e a desindustrialização são em parte explicadas pelos níveis e as características globais dos investimentos em tecnologias de informação e comunicação (TICs), que representam um dos principais responsáveis pelos aportes mundiais em pesquisa e inovação. $\mathrm{O}$ panorama das telecomunicações passou a ser de competição em escala mundial, alianças estratégicas entre empresas, novos e diversificados serviços com custos e preços decrescentes e de alta intensidade de P\&D. Relatórios da UNCTAD (2005) e da OCDE (2006) mostram a globalização dessas atividades, em que inovações tecnológicas são realizadas por fornecedores globais de equipamentos. Verifica-se a concentração em centros de excelência instalados em locais com melhores condições para inovação e geração de conhecimento. Enquanto o escopo da P\&D em telecomunicações de natureza pública decresceu, a competência em P\&D ampliou-se internamente nas empresas multinacionais. 
dependente das importações no setor das TICs, dados, nos últimos anos, os índices amplamente negativos na balança comercial. Se por um lado esse quadro denota o dinamismo, por outro evidencia a desarticulação da indústria nacional. Outrora detentor de padrões próprios no campo das tecnologias de telecomunicações, o país perdeu capacidade de influir no contexto tecnológico internacional nessa área ao longo do tempo. ${ }^{19}$

O modelo das agências reguladoras no cenário da administração pública brasileira já ensejou exame aprofundado acerca do poder normativo e da discricionariedade técnica de que são legalmente dotadas, visto seu poder para a um só tempo expedir normas e fiscalizar setores e atividades criticamente assentados no interesse público. ${ }^{20} \mathrm{O}$ exercício da competência técnico-discricional e da função normativa do regulador emana de sua lei instituidora e decorre do alto dinamismo do próprio desenvolvimento tecnológico do setor regulado.

Porém, a despeito da discricionariedade técnica legalmente detida pela ANATEL, o conjunto de atividades e iniciativas acima descritas somente revela-se legítima à luz da prevalência de alguns princípios norteadores, como o interesse público, eleitos segundo parâmetros conceituais que merecem ser elucidados, como se verá a seguir.

${ }^{19} \mathrm{O}$ Brasil não está isolado nesse tipo de preocupação. Movimentações são observadas na Índia e da Rússia para o desenvolvimento da indústria local nesse setor. Na Rússia, a Ericsson assinou um acordo estratégico de parceria com a Fundação Skolkovo para desenvolvimento de um centro de inovação. Na Índia, o órgão regulador, a TRAI, estabeleceu em abril de 2011 uma política agressiva que pretende, até 2020, elevar a 50\% o índice de equipamentos de telecomunicações a serem produzidos por empresas indianas. Para detalhamento das medidas da TRAI, conferir: http://www.trai.gov.in/.

${ }^{20}$ Note-se que a LGT não conferiu à ANATEL o poder de legislar, mas ditar normas e aplicar comandos da própria LGT, de outras leis que disciplinam o setor e de decretos sobre políticas de telecomunicações. O regulamento é ato normativo secundário geral expedido pelo Poder Executivo no exercício do poder regulamentar, cujo objetivo é facilitar a execução da lei e especificá-la de modo praticável (SUNFELD 2007 e MARQUES NETO 2005). 


\section{Teorias da regulação em face da atuação estatal no contexto das telecomunicações}

A busca dos parâmetros conceituais de reflexão pode encontrar nas teorias regulatórias norte-americanas elementos para aprofundar a crítica ao direito, quando a administração do Estado se investe em tarefas de planejamento, prestação de serviços, provisão e implantação de infraestrutura e de previsão de riscos, impulsionado pelo dinamismo científico e tecnológico. A adequada orientação do setor de telecomunicações do Brasil justifica a importância de se investigar a orientação da regulação estatal em direção à conformação de um espaço público mais amplo, dinâmico e favorável à retomada dos esforços orientados à $\mathrm{P} \& \mathrm{D}$, considerando o conjunto de efeitos sociais, econômicos e políticos que esse movimento engendra e seus possíveis impactos.

A experiência da reestruturação das telecomunicações no Brasil é reveladora não apenas da abertura do direito pátrio à absorção de um modelo típico da jurisdição do common law norte-americano de agência reguladora setorial, instituição estatal caracterizada como instância de "espaço público para além da esfera representativa" (ARANHA 2005, p. 21). Vai além. Verifica-se a configuração de uma "mescla pragmática" inovadora (CASTRO 2012, p. 199-200), ${ }^{21}$ que passou a valorizar a assimilação de elementos técnico-científicos na nova institucionalidade, integrando-os ao direito. Ilustra uma certa renovação dos referenciais da classificação tradicional do que seja "direito público" e "direito privado" em matéria de concessões de serviços públicos.

A esse respeito, estudo comparado abrangente de Aranha (2005b) investiga as semelhanças, diferenças e ausências das políticas públicas brasileira e norte-americana de telecomunicações em dois momentos normativos históricos de ambos os países, sob a ótica das políticas públicas, estrutura estatal de controle setorial, divisão conceitual de serviços de

21"Mescla pragmática", no dizer de Castro, corresponde ao ambiente mental criado nas profissões jurídicas que facilitou o retorno das "formas" da jurisprudentia do common law, em decorrência da consideração de conhecimentos especializados, com base na pesquisa técnico-científica. 
telecomunicações, atribuição de competências aos órgãos estatais e contextualização do surgimento dos órgãos reguladores nacionais. $\mathrm{O}$ estudo conclui pela comensurabilidade entre as duas experiências nacionais a partir das modificações normativas brasileiras de meados da década 1990.

Com efeito, não se pode ignorar a existência, no direito norteamericano, de consistente e copiosa teoria da regulação. Ao contrário, a despeito da construção teórica brasileira sobre a regulação, da singularidade da experiência vivida pelo Brasil e das distinções entre o legado do direito continental e da common law, constata-se clara oportunidade de examinar comparativamente o escopo teórico que reveste a regulação naquele país.

A partir das lições dalí extraídas, pode-se amoldar a reflexão às peculiaridades do nosso sistema jurídico, da configuração do Estado em nosso país, e das condições econômicas e sociais aqui prevalescentes.

\section{As teorias regulatórias e uma nova teoria geral da regulação de Horwitz}

Embora tenha sido desenvolvida para analisar o processo regulatório dos EUA, a abordagem proposta por Robert Britt Horwitz (1989), em seu livro The Irony of Regulatory Reform: The Deregulation of American Telecommunication, pode ser adaptada para o caso brasileiro, provando ser um útil e vigoroso instrumento de análise.

Nossa organização e instituições políticas são suficientemente similares às norte-americanas para que seja possível usar os mesmos métodos e conceitos após adaptá-los ao caso pátrio. Isto é, os principais atores e institutos do processo regulatório no Brasil são os mesmos que aqueles no processo americano: agência reguladora, Executivo, Congresso (Câmara, Senado e comissões), Judiciário, empresas operadoras e fornecedores, consumidores e outros grupos de interesse. Além disso, a organização interna de cada um destes grupos tem muitas similaridades com o respectivo grupo americano. Ao mesmo tempo, existem diferenças entre o Brasil e o EUA quanto aos processos, organizações e instituições políticas que não se pode desconhecer. Tais diferenças não invalidam o uso da abordagem de Horwitz ao caso brasileiro, pelo contrário, tornam mais interessante a tarefa.

Ao descrever a história das comunicações nos EUA para fundamentar a construção de uma nova teoria geral da regulação, contra o pano de fundo 
das teorias modernas do Estado, Horwitz revela o mosaico de forças econômicas, políticas, jurídicas e tecnológicas - que fragilizou a regulação tradicional das telecomunicações naquele país e precipitou a fase da desregulação nos anos 1980. Delineia três períodos distintos da regulação e os três tipos de agências resultantes, sobretudo a criação da Comissão Federal de Comunicações (FCC) e o desmantelamento da AT\&T, que passam a representar uma nova estrutura institucional de poder federal e econômico no sistema político norte-americano. Apesar de aspectos negativos, como o burocratismo, as agências reguladoras podem ser vistas como mecanismos de racionalização no capitalismo avançado.

Segundo Horwitz, as teorias da regulação emergem de duas fontes principais. De um lado, a noção de bem-estar econômico, referindo-se à crença na capacidade de intervenção do Estado para garantir tanto redistribuições econômicas socialmente desejáveis, quanto a eficiência da economia em geral.

As teorias tradicionais de regulação que se filiam a essa corrente centram-se em torno do conceito de interesse público que está enraizado no bem-estar econômico. O interesse público legitima a intervenção estatal limitada no mercado.

De outro lado, situam-se as teorias associadas à teoria política, da qual emergem vários modelos de dinâmica política que se propõem a explicar a gênese da regulação e o comportamento das agências reguladoras. Teorias de regulação enraizadas na teoria política são geralmente teorias que afirmam que as agências reguladoras servem a interesses privados, sejam eles os setores regulados, sejam os próprios reguladores.

$\mathrm{Na}$ visão do autor, para entender a regulação é necessário separar aspectos de gênese e a operacionalidade, para voltar a reuní-los em momento subsequente da análise. A criação de qualquer corpo regulatório específico está intrinsecamente associado às circunstâncias históricas de contorno.

Ele recomenda ser preciso examinar o funcionamento da agência reguladora uma vez estabelecida, com base nos complexos comportamentos organizacionais e restrições institucionais. Adverte que a própria dinâmica da operação regulatória pode mudar no tempo, devido a alterações das relações históricas com a indústria e transformações dentro e fora da 
agência. Alerta, ainda, para a confusão entre a gênese histórica e a operacionalidade real das agências, também conhecida como "falácias de origem e efeito", principal deficiência da literatura no assunto.

No capítulo 2 de seu livro, Horwitz apresenta levantamento minucioso das principais teorias regulatórias e as classifica de acordo com os respectivos pontos fracos e fortes.

Para melhor apresentar esquematicamente esse levantamento, vai-se recorrer a uma tabela sinóptica, com o intuito de oferecer uma visão geral desses elementos e suas relações (Tabela 1).

Evidentemente, há que se ressalvar que o recurso a modelos esquemáticos implica necessariamente abandono de detalhes e interrelações próprias de sistemas complexos, em benefício da clareza.

Na primeira coluna da Tabela são listadas e brevemente descritas as distintas teorias regulatórias elencadas pelo autor e relevantes para os objetivos deste estudo, quais sejam: Public interest theory, Perverted public interest theory or regulatory failure, Conspiracy theory, Economic captureconspiracy theory, Organizational theory, Capitalist state theory.

$\mathrm{Na}$ segunda coluna, apresentam-se os principais pontos fortes, identificados à luz dos critérios de origem histórica e real funcionamento das agências.

$\mathrm{Na}$ terceira coluna, finalmente, são apontados os pontos fracos assim identificados sob os mesmos critérios de gênese e operacionalidade.

Segundo Horwitz, as teorias do "interesse público" e as teorias da "captura", incluindo as teorias econômicas da regulação de autores da Escola de Chicago, integram dois pólos extremos de abordagem e de argumentação sobre a regulação pública de mercados.

O primeiro grupo pensa a regulação como correção das falhas de mercado com vistas à promoção do bem-estar. As justificativas do interesse público para a regulação são baseadas nas premissas de que a intervenção é justificada porque ela leva a uma melhoria no bem-estar social. A regulação, segundo a teoria do interesse público é uma resposta legítima a uma falha de mercado - monopólio natural ou externalidades. 


\begin{tabular}{|c|c|c|c|c|c|c|}
\hline & 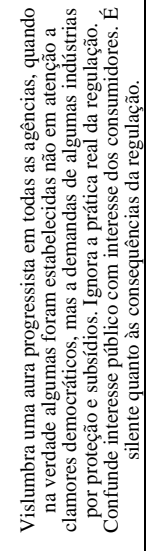 & 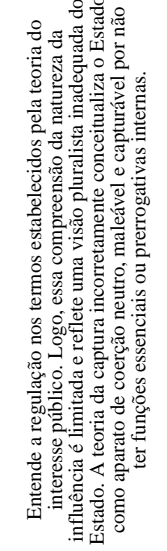 & 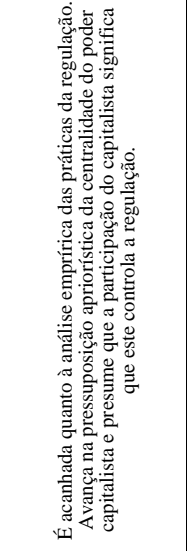 & 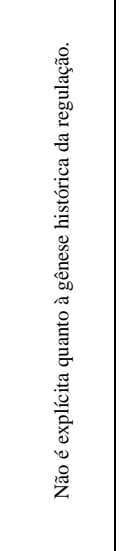 & 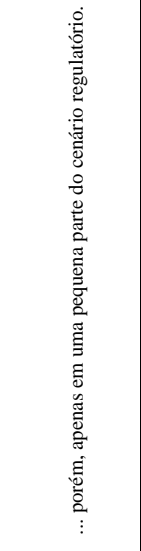 &  \\
\hline & 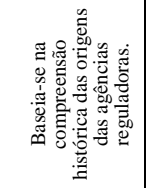 & 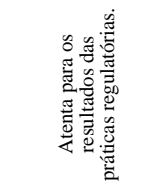 & 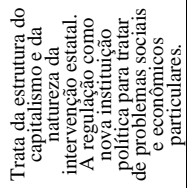 & 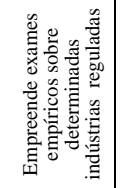 & 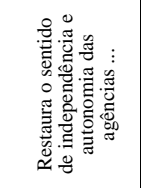 & 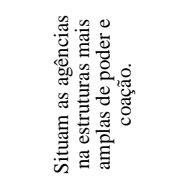 \\
\hline 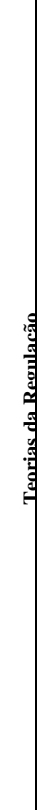 & 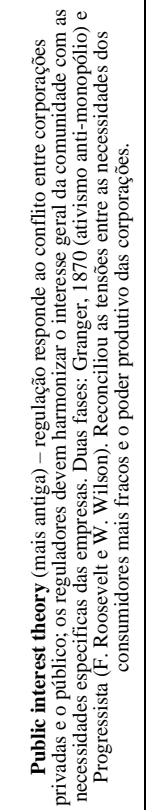 & 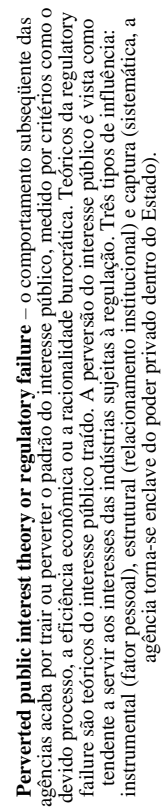 & 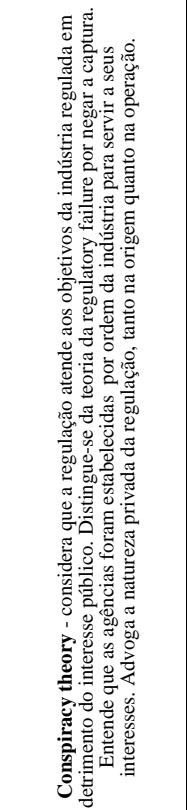 & 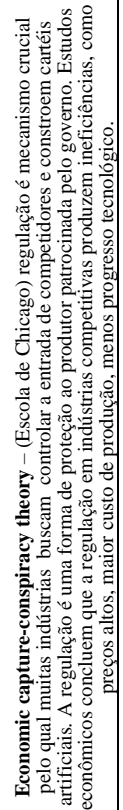 & 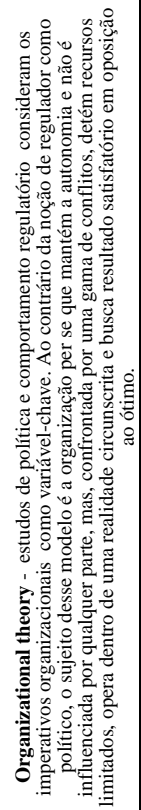 & 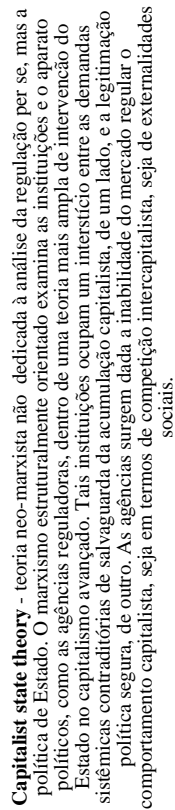 \\
\hline
\end{tabular}

Revista de Direito, Estado e Telecomunicações, v. 5, n. 1, p. 107-134 (2013)

DOI: https://doi.org/10.26512/lstr.v5i1.21564 
O segundo grupo pensa a regulação como interação de interesses privados orientados exclusivamente para a busca da maximização de seus benefícios. As teorias do "interesse público" afirmam que a regulação de mercados consiste em deixar com a iniciativa privada a responsabilidade da oferta, garantindo, dessa maneira, as vantagens inerentes ao sistema de mercado, ao mesmo tempo em que se restringe parcialmente a autonomia de decisão do empresário, substituindo seu comportamento maximizador de lucros por normas administrativas que garantam um resultado socialmente aceitável no mercado.

Horwitz ressalta que até a década de setenta a explicação dominante sobre a origem e o propósito da regulação era a teoria do interesse público, segundo a qual regulação é instituída com o propósito de defender o interesse do público contra perdas de bem-estar associadas a falhas de mercado. A teoria do interesse público tem como hipótese fundamental que a regulamentação é produzida por pressões públicas de modo a corrigir distorções que não podem ser eliminadas pela ação das livres forças do mercado. A teoria do interesse público supõe portanto uma premissa comportamental para os legisladores/reguladores como maximizadores do bem-estar social, buscando corrigir problemas de falhas de mercado. $\mathrm{O}$ autor alerta, no entanto, para o fato de que a observação caso-a-caso das indústrias efetivamente reguladas mostra que não existe uma correlação forte entre regulação e falhas de mercado. Considera que as premissas desta teoria sejam um tanto ingênuas, sendo sua falha mais grave não oferecer uma explicação clara de como a demanda por regulação é transformada em regulação efetiva. ${ }^{22}$

${ }^{22}$ Complementarmente, segundo Richard Posner (1974), a teoria do interesse público (TIP) presume que a TIP centra-se na ideia de que os que buscam instituir uma regulamentação o fazem com o fim de perseguir o interesse público relacionado a determinados objetivos, ao invés de um grupo ou setor. Portanto, o objetivo da regulação é alcançar certos resultados desejados em circunstâncias em que o mercado falha. As principais críticas a TIP: a) há um ceticismo referente ao "espírito público e desinteressado" dos regulamentadores; b) a TIP desconsidera as influências do poder econômico e a prevalência da captura na regulação; c) ela também desconsidera a competição por poder entre os grupos de pressão; e d) há evidências históricas que mostram que a regulação não está fortemente correlacionada com a existência de falhas de mercado. 
Uma explicação alternativa que, segundo o autor, não sofre do mesmo desencontro entre previsão e realidade é a teoria da captura, também conhecida como teoria dos grupos de interesse. Esta teoria se baseia na observação empírica de que a regulação tende a favorecer os produtores economicamente mais fortes, que capturam a regulação como forma de proteger seus interesses.

Diferentes vertentes da teoria da captura existem desde o século passado, sendo um exemplo a visão marxista segundo a qual as grandes firmas seriam sempre beneficiadas pelo governo. Sob este ponto de vista, as firmas demandariam regulação para efetuar transferências a seu favor e criar barreiras de entrada para proteger suas rendas de monopólio ou gerar custos para seus concorrentes potenciais e efetivos. Mesmo que a regulação tivesse surgido inicialmente com o propósito de corrigir alguma falha de mercado, a teoria da captura prevê que ela acabaria sendo distorcida para atender os interesses das firmas, prejudicando assim os consumidores. Embora esta teoria tenha um apelo intuitivo maior do que a teoria do interesse público, ela não se baseia em nenhum modelo analítico que explique quais grupos irão capturar o regulador e quem será penalizado. Além disto ela não consegue explicar por que muitas vezes firmas pequenas conseguem capturar o processo regulatório, nem explicar diversas outras regularidades observadas na prática. ${ }^{23}$

Por seu turno, nova teoria preconizada pelo autor acolhe da teoria estruturalista a noção de que o Estado é um ator dentro da democracia capitalista. As ações do Estado são importantes e não são dirigidas pelos capitalistas. No entanto, a autonomia dessas ações é sujeita a restrições. O Estado pode funcionar somente dentro de parâmetros constituídos pelos dois limites fundamentais do sistema, de acumulação e de legitimação, ou seja, deve salvaguardar as condições de continuidade do crescimento e

${ }^{23}$ Adicionalmente, vale ressaltar outras considerações importantes sobre a teoria da captura (TC): a) a TC não explica como as agências se tornam controladas pela indústria; b) embora existam evidências que sustentem a TC, há também evidências que são inconsistentes com ela, por exemplo, a existência de subsídios cruzados; c) a TC tem dificuldades para explicar porque muitas indústrias foram reguladas e depois desreguladas; d) as limitações informacionais podem limitar o interesse das ações regulatórias; e) há dificuldade de identificar as partes envolvidas e suas preferências.

Revista de Direito, Estado e Telecomunicações, v. 5, n. 1, p. 107-134 (2013)

DOI: https://doi.org/10.26512/1str.v5i1.21564 
desempenho econômico, e ao mesmo tempo responder às demandas democráticas relativas à equidade e ao devido processo.

$\mathrm{O}$ autor faz um empréstimo seletivo de noções do neo-marxicismo, mas também utiliza teorias neo-weberianas para analisar como a regulação atua na prática, pois uma teoria abrangente deve contar separadamente tanto com a gênese, quanto com a operacionalidade das agências. A história e a análise das decisões reais devem ser consideradas dentro do contexto da política e das condições econômicas, levando em conta não apenas as diferenças entre as agências, mas também as distinções nas condições políticas históricas.

Segundo a abordagem de Horwitz, não há caminho infalível para predizer qual indústria deve ser regulada e qual não deve ser. Não se trata de uma proposta de previsão ou uma teoria de modelagem, mas uma teoria histórica. Mas ao mesmo tempo, todas as agências estão situadas dentro de uma estrutura geral de poder político e, dentro desse contexto, são compelidas pelas necessidades de acumulação do modo capitalista de produção e pelas demandas de legitimação inerentes à democracia política. Devido à temporalidade e mudanças na dinâmica política, há fatores que orientam o comportamento regulatório, não havendo um padrão único. $\mathrm{O}$ texto ressalta que a regulação é um espaço regrado de manifestação política ao longo do tempo e não uma forma de relação polarizada entre atores predeterminados. A projeção política dos atores setoriais permite o enfoque da questão regulatória como a presença de diversos atores setoriais em torno de um regime jurídico regulatório visto como espaço de postulação de interesses legítimos.

$\mathrm{O}$ autor conclui que, de modo geral, a desregulação pode aliviar o protecionismo, a incompetência do regulador e o formalismo burocrático, mas, ao mesmo tempo, pode reduzir os padrões estabelecidos de operação e prejudicar a estabilidade global das indústrias de infraestrutura. No curto prazo, as eficiências induzidas pela desregulação podem ser de um tipo que debilitam as características dos serviços de infraestrutura. A desregulação também limita o acesso democrático ao processo de elaboração política. Essas tendências podem levar à reemergência de demandas sociais e econômicas que historicamente requereram controles regulatórios. De fato, muitos movimentos de reregulation já teriam reiniciado quando da escrita do livro, como na indústria de aviação civil e nas próprias 
telecomunicações. Como os problemas que as agências vieram corrigir começaram a reaparecer, acredita o autor que a regulação também reapareceria, ainda que em novo formato.

\section{Conclusão}

A transformação da política em administração no mundo moderno, criticada por Arendt (2011, p. 18), ensejou a politização da tecnologia e do conhecimento especializado no mundo contemporâneo. Área de interesse de historiadores, filósofos, sociólogos e juristas, a abordagem teórica da ciência e tecnologia e de sua gestão pelos instrumentos do Estado deve levar em consideração o contexto sócio-histórico em que se inserem, indo além dos elementos teórico-cognitivos. Se uma premissa do conhecimento científico é ser passível de refutação e as respostas científicas são dadas conforme o nível relativo de conhecimento, há de se reconhecer que o técnico implica opção política. Novos desafios engendrados pela dinâmica tecnológica passam a ser exercidos diretamente sobre a esfera pública. A ciência e tecnologia não se portam como esfera neutra e a direção que se queira dar ao conhecimento técnico é questão política de primeira grandeza que, como tal, não deve ser decidida apenas por cientistas, burocratas e políticos. A participação da sociedade, em suas diferentes dimensões, é imperativo necessário.

Assim, entende-se que a atuação da agência reguladora das telecomunicações, por sua própria dimensão multidisciplinar, explicitada na primeira parte deste texto, não pode se esquivar de buscar a composição de interesses oferecida pela perspectiva pluralista e sistêmica. As ideias dos autores examinados são particularmente apropriadas para desvendar a lógica que rege a dinâmica de relações entre ciência e tecnologia $(C \& T)$ e a sociedade, e a atuação da agência reguladora das telecomunicações em particular, no contexto social, político e jurídico-institucional em que se colocam.

Vale recordar a acurácia do ensinamento de Sundfeld (1996, p. 150) de que "o Estado não exerce a autoridade pública sempre, em qualquer situação, ou na medida em que o quiser. Exerce-a se, quando e na proporção em que esta lhe tenha sido conferida pela ordem jurídica". 
Nesse sentido ganha relevo a proposição acerca da discussão estrutural sobre a abrangência e a intensidade da regulação estatal e sua oportunidade para elucidar "os limites, condicionantes, fundamentos e pressupostos da atividade reguladora estatal" (MARQUES NETO 2006, p. 9). Levando em consideração as condições históricas e o sistema jurídico brasileiro, a partir dela é possível indagar até onde pode ir o poder público na imposição ou no manejo de regimes regulatórios específicos sobre setores da economia. Marques Neto (2006) ressalta que, no contexto brasileiro, embora expressamente admitida na Constituição Federal, a regulação estatal deve-se balizar pelo princípio da subsidiariedade, segundo o qual a razão de interesse público torna legítima e justificável a restrição da liberdade econômica, pautada no princípio da livre iniciativa, mediante a incidência da regulação. É o que justificaria a inédita incursão, ora em exame, da atuação regulatória da ANATEL no campo do estímulo à $\mathrm{P} \& \mathrm{D}$, como instrumento de políticas públicas governamentais.

Ainda na lição de Marques Neto, a ideia de sistema está necessariamente subjacente à ideia de regulação exercida pelo Estado, ${ }^{24}$ a qual

"pressupõe ou o sistema econômico como um todo (e, nele, os valores da defesa da concorrência e dos direitos do consumidor), ou a identificação de um subsistema econômico (...) ou uma determinada indústria ( $\mathrm{e}$, dentro destes subsistemas, os valores que justificam a incidência regulatória, como o uso racional de um bem escasso, objetivos de políticas públicas específicas, hipossuficiências sociais e econômicas, etc.).” (MARQUES NETO 2006, p. 4-5)

Esse autor ressalta que, no contexto jurídico institucional de países como o Brasil, a regulação econômica, geral ou setorial, envolve necessariamente a perseguição de objetivos de interesse público, traduzidos em inputs extra-sistêmicos que são a um só tempo impostos pelo poder público, via políticas públicas, e filtrados e absorvidos por ele, via atividade regulatória.

Ao se alinharem, portanto, às políticas públicas para o setor, considerando seus intrumentos e suas competências legais, as iniciativas da ANATEL relativamente a condicionamentos e estímulos a $\mathrm{P} \& \mathrm{D}$ e produção

${ }^{24}$ Para aprofundamento da noção de teoria da autopoiese, conferir: TEUBNER, 1993. 
de bens e serviços de telecomunicações no país não se distanciam das boas práticas regulatórias e encontram-se sob o amparo do que preconizam as teorias regulatórias como atuação estatal legítima. ${ }^{25}$ É possível perceber que se encontram contemplados, em particular, elementos das teorias tradicionais de regulação que se filiam à corrente no bem-estar econômico centrada no conceito de interesse público, assim como a aspectos da Capitalist state theory, tal como descrita por Horwitz, além das recomendações do autor relativamente à atuação regulatória.

Com efeito, a história e a análise das decisões reais das agências devem ser consideradas dentro do contexto da política e das condições socioeconômicas, levando em conta não apenas as diferenças entre o contexto de cada agência, mas também as distinções nas condições políticas e históricas. Constata-se que o regulador brasileiro buscou agir perseguindo os objetivos do interesse público, mas levando em consideração as possibilidades e necessidades do setor privado. Nessa visão, a regulamentação torna-se desejável quando os resultados de mercados são ineficientes, e a intervenção estatal através da regulação por incentivo pode ser social e economicamente benéfica.

A partir desse breve estudo, é possível ainda constatar, a relevância da abordagem das teorias regulatórias norte-americanas para a análise da experiência brasileira, guardadas suas singularidades e ressalvas anteriormente explicitadas, sobretudo à luz da ênfase esposada por Horwitz nos aspectos relativos à gênese histórica e funcionalidade real das agências reguladoras, com vistas à constituição de novos espaços públicos e novas institucionalidades no campo das tecnologias da informação e das comunicações no Brasil e, em especial, no domínio das telecomunicações.

Uma consideração final merece registro. Sendo os riscos imprevisíveis, é preciso definir democraticamente o modelo de regulação da pesquisa e desenvolvimento em telecomunicações que a sociedade brasileira quer para si. A tecnologia não é boa, não é má per se; depende de sua aplicação. Hannah Arendt (2005, p. 11) já dizia que os homens não tardam a adaptarse às descobertas da ciência e aos feitos da técnica, ao contrário, estão à sua

${ }^{25}$ Conferir Informe $\mathrm{n}^{\circ}$ 17/2010/SUE/ANATEL, de 17 de dezembro de 2010, relativo à Proposta de Regulamento de Estímulo à PD\&I em Telecomunicações, em: http://sistemas.anatel.gov.br/ 
frente. A questão é em que direção se deseja usar o conhecimento técnico e científico e esta questão não pode ser resolvida apenas por meios tecnocientíficos. É uma questão política de primeira grandeza e, como tal, não deve ser decidida por apenas por cientistas, nem exclusivamente por gestores ou políticos.

\section{Bibliografia}

AGÊNCIA BRASILEIRA DE DESENVOLVIMENTO INDUSTRIAL (ABDI). Estudos Setoriais de Inovação: Indústria de Tecnologia da Informação e Comunicação. Abril de 2009. Obtido via WWW: http://www.abdi.com.br/.

ARANHA, Márcio Iório. Direito das Telecomunicações. Virtude Política e Abertura Estrutural das Agências Reguladoras: o caso das telecomunicações. In: PEREIRA, Cláudia Fernanda de Oliveira (org.). O Novo Direito Administrativo Brasileiro: o público e o privado em debate. Belo Horizonte. Fórum, 2010.

- Agência Reguladora e Espaço Público. In: Direito das Telecomunicações: estrutura institucional regulatória e infraestrutura das telecomunicações no Brasil. 2005a. GETEL/UnB. Série Grupos de Pesquisa $\mathrm{n}^{\circ}$ 2, vol.1.

Políticas Públicas Comparadas de Telecomunicações (BrasilEUA). Brasília: Centro de Pesquisa e Pós-Graduação sobre as Américas (CEPPAC), Instituto de Ciências Sociais, Universidade de Brasília. Tese de Doutorado, 2005b.

ARENDT, Hanna. A condição humana. Rio de Janeiro: Forense Universitária, 2005.

. Sobre a Revolução. São Paulo: Companhia das Letras, 2011.

BRASIL. ANATEL. Estudo Técnico para Atualização da Regulamentação das Telecomunicações no Brasil. Brasília. 2008.

BRASIL. MINISTÉRIO DAS COMUNICAÇÕES. Exposição de Motivos da Lei Geral de Telecomunicações. E. M. nº 231/MC, Brasília, 10 de dezembro de 1996.

BRASIL. MINISTÉRIO DA CIÊNCIA E TECNOLOGIA. Sociedade da Informação no Brasil: Livro Verde. Brasília: MCT, 2000. 
CANOTILHO, José Joaquim Gomes. Direito Constitucional. $5^{\text {a }}$ ed., Coimbra: Almedina, 1991.

CASTELLS, Manuel. A sociedade em rede. A era da informação: economia, sociedade e cultura. São Paulo: Paz e Terra, 1999.

CASTRO, Marcus Faro de. Formas jurídicas e mudança social: interações entre o direito, a filosofia, a política e a economia. Saraiva: São Paulo, 2012.

ERBER, Fábio. O padrão de desenvolvimento industrial e tecnológico e $o$ futuro da indústria brasileira. In: Revista de Economia Contemporânea. Vol. 5. Edição Especial. 2000.

ERBER, Fábio; AMARAL, Leda. Os centros de pesquisa das empresas estatais: um estudo de três casos. Estudo realizado pela Escola de Administração da FGV por solicitação do MCT e do Banco Mundial, dentro do programa PADCT II. 1993.

FERRAZ Jr, Tercio Sampaio. Agências Reguladoras: legalidade e constitucionalidade. 2011. Obtido via WWW: http://www.terciosampaioferrazjr.com.br/

HORWITZ, Robert Britt. The Irony of Regulatory Reform: The Deregulation of American Telecommunication. Oxford University Press, 1989.

MARQUES NETO, Floriano de Azevedo. Regulação estatal e interesses públicos. São Paulo: Malheiros, 2002.

Agências Reguladoras Independentes: fundamentos e seu regime jurídico. Belo Horizonte: Fórum, 2005.

. Limites à abrangência e à intensidade da regulação estatal. In:

Revista Eletrônica de Direito Administrativo Econômico. Vol. 4, novembro/dezembro/2005-janeiro, 2006.

POSNER, Richard A. Theories of economic regulation. [S.1.]: NBER, 1974. (Working paper $\mathrm{n}^{\circ} 41$ ).

SUNDFELD, Carlos Ari. Introdução às agências reguladoras. In: Direito Administrativo Econômico. São Paulo. Malheiros, 2000.

- Procedimento administrativo fiducial na regulação das telecomunicações. In: Revista de Direito Público da Economia, ano 2, $\mathrm{n}^{\circ}$ 7, jul./set. 2004. 
. A regulação das telecomunicações: papel atual e tendências futuras. In: Revista eletrônica de direito administrativo econômico, $\mathrm{n}^{\circ} 8$, novembro/dezembro/2006-janeiro, 2007.

. Fundamentos do Direito Público. São Paulo. Malheiros, 1996.

TEUBNER, Gunther. O direito como sistema autopoiético. Lisboa: Fundação Calouste Gulbenkian, 1993. 
